\title{
Micro and Macroeconomic Approaches Regarding Foreign Direct Investments Throughout Offshore Entities
}

\author{
${ }^{*}$ Alexandru Trifu ${ }^{1}$, Ecaterina Pojoga ${ }^{2}$ \\ ${ }^{1}$ University, Petre Andrei of Iasi, Romania \\ ${ }^{2}$ Moldavia State University Chisinau, Romania \\ *alexandru.trifu@gmail.com
}

\begin{abstract}
Offshore companies represent a key-link of the current operations of the multinationals, banking institutions and, even, of the small and medium enterprises (SME) and are able to perform complicated tasks in a special business environment. These jurisdictional entities offer, mainly, fiscal benefits, comparative with other types of jurisdictional entities. The advantages are targeting the enterprises or companies which establish their social headquater, or to individuals who are resident in these territories. The final scope is represented by attracting the expanding companies, by attracting capital and stimulating the rise of the necessary activities to ensure economic and social balance, so desirable in the economic games of win-win type. Therefore, we are in the presence of fine plaition of micro approach with macroeconomic one. On the first side, the desire of transnationals to obtain profits with less efforts and investments and, on the other hand, globalization (influenced by these entities) pursuit the shrinkage of all markets and businesses all around the world, inclusive using the offshores centers (or „fiscal paradises”). These institutions of free market are actioning both on the developed and developing countries. The last ones are affected by the imposibility of tax collect to the national budget and in the infrastructure investments. At the same time, using offshore companies in offshore zones, the multinationals gain neloial competitive advantages over the other companies, unable to spread theirs economic power and influence. We may speak about a sound offshore industry, which has turned into global business and range of activities. We try to underline the importance of the general development process in the actual world and, first of all, the direct connection beteen investments and offshore activities, in the benefit of either parties. It is an organic liaison between investments and offshore entities, including transitional hard developing countries as Romania.
\end{abstract}

Key words: Offshore company, international trade, tax evasion, investments, globalization, FDI.

\section{Introduction}

General Approach: In everyday language, tax havens are those areas that offer a wide range of tax advantages to offshore companies registered in that territory (the original English term - tax haven means tax shelter). An offshore company can operate under favorable tax conditions only if registered in a tax haven. In accordance with the principle stated above, the company must operate outside the territory of registration. In traditional tax havens, companies operate in support of an extremely well organized legal mechanism, meaning that, in that country, the law provides favorable tax conditions for offshore companies. It should be noted that, by not paying the tax, the company does not violate the law; on the contrary, according to the law, the company is partly or entirely exempted from tax. Tax havens play a key role in emphasizing the capital movement and the creation of complex networks of transactions and interactions between states, multinational companies, extremely wealthy individuals and ordinary individuals. During the last five years, the controversial term of tax haven has turned into the more precious term of offshore financial center. The offshore section of international finance (about 5.2 trillion dollar investments ${ }^{1}$ are accumulated in these areas in the last decade) is a key part of the current operations of multinational corporations, banking institutions, financial professionals and even medium and small companies. For 2010, for example, UNCTAD revealed that there were no significant growth of global FDI, with 1,122 billion \$, but below the pre-crisis average of 2005-20072. Offshore areas are considered a threat to the global financial system because they allow a greater flexibility in drawing up financial statements. They can facilitate tax evasion and can cover up the maneuvers of the authoritarian political regimes. It is estimated that the cumulative amount of earnings from taxes

\footnotetext{
${ }^{1}$ Diamond, W. \& Diamond, D. (2003). „Tax Havens of the World”, Matthew Bender\&Co,Lexis Nexis, p.83.

$2 * * *$ Euro stat News release, June 2011.
} 
obtained by the 70 offshore jurisdictions of the world is about 200 billion euro annually ${ }^{3}$ and much more nowadays. Compared to other legal entities, these legal entities provide tax advantages to companies setting their headquarters or individuals residing in these territories. The aim is to attract growing companies, raise capital and stimulate those activities that are necessary for ensuring economic and social balance. The tax facilities used for achieving the desired goal are manifold: exemption from the tax on incomes/ profits or the application of extremely low tax rates. Another key feature is the protection by law of the commercial or financial transactions made by individuals or companies.

In order to ensure a favorable tax regime, these entities constantly adapt their tax legislation to the international trends. One should not neglect the fact that some tax havens benefit from tax treaties in order to avoid the double taxation of the incomes. Other features concern: developing a banking system with no restrictive regulations and constraints that provides fast operations inside and outside the borders, no or little control of exchanges, with the exception of those related to foreign currencies as well as providing highly functional means for communication (telephone, internet connections, air services). All these features mentioned above help create a framework for the development of business operations, including investments, with or without tax incentives, the only condition being the compatibility of these local entities with the legislation. The classification of tax havens does not aim at dividing territorial entities, but rather at pointing out the grounds on which these entities are given such attributes, offering a few examples. Tax havens can be divided into primary and secondary. Seven types of countries can be identified in the first category 4 .

Countries with no income or capital appreciation taxes (called "zero Havens" or "pure Havens"): Anguilla, Aruba, Bahamas, Bahrain, Bermuda, Cayman Islands, Madeira, Marshall Islands, Mauritius, Saint Vincent, Turks and Caicos Islands and Samoa.

- Countries with low income taxes (fixed rates set by the authorities or combined with exemptions or reductions provided by double taxation treaties): Cyprus, Labuan, Liechtenstein, Malta, Oman, Switzerland, Jersey, Guernsey and BVI.

- Countries where taxes are set on a territorial basis: Costa Rica, Hong Kong, Liberia, Malaysia, Panama, Philippines, Venezuela, Great Britain. In these countries, taxpayers are granted exemptions for the benefits obtained through operations made outside the territory.

- Countries that offer special treatments to offshore companies and holding companies: Austria, Hungary, Luxembourg, Netherlands, Netherlands Antilles, Singapore, Thailand.

- Countries where companies producing for export are exempted from taxes: Ireland and Madeira (Portugal).

- Countries where international business companies (IBC) are offered tax advantages - companies that are investment oriented or not, but which qualify as privileged offshore financial companies: Antigua, Bahamas, Barbados, BVI, Isle of Man, Montserrat and Santa Lucia.

- Countries that offer specific tax advantages to banking entities and other financial institutions with offshore activities: Hong Kong, Madeira, Malaysia, Philippines, Singapore, Thailand.

On the other hand, Foreign Direct Investments (FDI) is considered an international category of investment that affects the objective of obtaining a lasting interest by an investor in one economy into an enterprise resident in another (or third) economy. Inward and outward flows of Foreign Direct Investments, including those provided by offshore entities in 2010, annual in the world, were of $1,243,671$ million $\$$ at current prices and current exchange rates. From this amount, approximately even was the proportion between developed countries and developing ones: 601,906 mil. \$ and 573,568 mil. $\$ 5$.

\section{Conclusion}

Many times, important people found themselves in the position of making the rules, as well as that of beneficiary, for them or the companies they run. This success recipe has brought along billions of Euros. And what better shelter for standing in the background is there than an offshore company, based in one of the tax haven islands which do not require any taxes or shareholder identification? If the '90s it was fashionable for a Romanian businessman to hide his identity in a tax haven, and then, under the cover of

\footnotetext{
${ }^{3}$ Diamond, W. \& Diamond, D. (2003). „Tax Havens of the World”, Matthew Bender \& Co, Lexis Nexis, p.93.

4 Diamond, W. \& Diamond, D. (2003). „Tax Havens of the World”, Matthew Bender \& Co, Lexis Nexis, p.116 $5 * * *$ UNCTADstat-www.unctadstat.unctad.org
} 
the foreign investor in search of business, to come to Romania and buy a factory from the former State Ownership Fund portfolio, today the situation has become much more sophisticated. In addition, the ways of becoming the "strategic investor" are much more difficult to reach. According to the new legislation in the field, direct investments through firms located in tax havens have become more easily accepted by the authorities; foreign companies with less clear identities are also allowed to take part in the privatization of state companies. Therefore, after a quick review of the origin of the capital invested in Romania in the last few years, in a classification regarding the volume of money placed, one will almost always find Cyprus and on the first 20 places - countries such as Liechtenstein, Luxembourg or even the Netherlands Antilles. The fact that nobody has made serious efforts to see whom gets the former state-owned enterprises is also relieved by the post-privatization analysis. If we look only at the events of the last five years and investigate the privatization of the state owned companies, we will find that only the companies registered in tax havens, and having, in truth, a clean image, have been successful when they knocked on the doors of the competent state institutions. Investment funds managed by offshore registered in tax havens are perfectly insinuated into the Romanian economy, which is a sign that paid professionals have done their job excellently. They can be found within the private part of the economy, where their presence was unlikely to create suspicion, by mixing among the hundreds of thousands of companies running small or large businesses. Offshore companies have managed to take over significant packages or even the control of private companies and to accumulate significant share packages even in key areas or strategic industries. Monitoring their involvement has already caused an unprecedented storm in Europe and even at international level.

The situation of the national economy regarding the new requirements of the European Union does not sound very optimistic. At the end of last year, statistics showed that in Romania over $90 \%$ of the money laundering operations and major acts of tax evasion are made by firms held by companies registered in tax havens. In a report made by the National Office for Preventing and Combating Money Laundering the following is written in black and white: "Important foreign transfers to Cyprus, Monaco, Luxembourg, Liechtenstein, Virgin Islands, San Marino, Bahamas, etc. have been found. The large amounts transferred to the Netherlands -1.700 million Euros (Netherlands Antilles) also draw the attention. In some cases, these funds were returned to Romania under the form of private foreign loans granted by foreign firms to companies that produced dirty money, which they invested in profitable economic areas. On should notice that the amounts come from Switzerland, Monaco, Luxembourg, Liechtenstein, etc." The levels and rates of Romanian taxes, as well as the other contributions, which the taxpayer - physical or legal person has to pay, are continuously rising; the illusion that sometimes certain tax aspects decrease is precisely due to the fact that a decrease is compensated and surpassed by an increase in another tax item. Romania is a country that, at least at a declarative level, has firmly embarked on the road to modernization and innovation in all the areas of the social, political and economic life in order to enter the European and Euro-Atlantic economic and defense structures. Under these changes, in the context of the imbalances (which are normal up to a point) in all the compartments of the society, the subject of the modern, even scientific forms of economic and financial crime, benefitting from the technology and information society, becomes ever more present, more pressing, more serious and more aggressive and therefore it is required to be solved whatever difficulties, drawbacks and traps it may bring forward. Tax evasion is the result vector of the defaults, inconsistencies and permissiveness of an imperfect legislation, which are unhappily assimilated with a poor and heavy applicability, with structures that are full of opportunistic and unprofessional people pursuing personal gains.

In addition, excessive taxation causes evasion. Living standards, public awareness and civic culture infiltrated in the collective memory are all nuanced but important elements in the study, analysis and identification of solutions for combating the rod, which ultimately violates one of the essential principles of the constitution of any state subject to the rule of law: "under the law all citizens are equal." One of the most difficult issue brought to the public by the press, which addresses both tax authorities and lawyers, is the identification and knowledge of the large number of laws establishing tax liabilities and providing details regarding the establishment of the matter subject to taxation and the collection. Ambiguity, contradictions and instability are the words for defining the legal framework and the natural consequence of such a situation is the lack of correlation between the solutions provided by various courts when judging the various disputes on the subject that we are discussing in this paper. Just like in any science, Economic theory must be naturally and effectively related to practice; in this area, the legal and institutional elements must be in a professional and productive interdependence. It is necessary to unify the financial and tax legislation by developing and adopting a Tax Code, which ought to set uniformly the tax liabilities, the procedure for determining and imposing them, the obligations and rights 
of the taxpayer and of the tax authorities, contraventions and infractions, as well as other sanctions in strict accordance with the Constitution. Adopting and implementing a modern and transparent legal framework, together with motivating the personnel of these institutions would be likely to reduce the harmful effects of this economic rod of the contemporary world and to create the premises for better cooperation with each taxpayer, but also for the development of his civic consciousness regarding his obligations to the State, which he must perceived as a protector and not as a spoliator. In essence, Foreign Direct Investments have not achieved a leap in productivity and neither determined the Romanian economy as an innovative player in the European market, said experts in Macroeconomics. The explanation is that foreign capital flows were not oriented to those economic sectors that produce sustainable economic growth, but to the speculative sectors such as retail and real estate.

\section{References}

Diamond, W. \& Diamond, D. (2003). Tax Havens of the World, Matthew Bender \& Co., Lexis Nexis. www.unctadstat.unctad.org (viewed March 2012).

Eurostat Newsrelease, June 2011. 